\title{
ANTAGONISTS OF COLLETOTRICHUM MUSAE ASSOCIATED WITH BANANA FRUIT SKIN
}

\author{
DEVIKA M. DE COSTA*, B.S. AMARADASA and R.N.B.P.M.R.C.L. WEGIRIYA \\ Department of Agricultural Biology, Faculty of Agriculture, University of Peradeniya, \\ Peradeniya.
}

(Received: 27 Septembr 1996; accepted: 03 May 1997)

\begin{abstract}
Potential antagonists of $C$. musae associated with the fruit skin of banana were investigated. The ability of inhibition of $C$. musae by the above antagonists was tested in vitro and in vivo. Fruit skins of banana, both resistant to anthracnose \{var. Seenikehel (ABB)\} and highly susceptible to anthracnose \{var. Embon (AAA)\} were used as the sources of antagonists. Antagonists of C. musae were associated only with the var. Seenikehel. Nine bacterial isolates and a fungus associated with var. Seenikehel showed in vitro inhibition of C. musae. Out of nine bacterial isolates, 6 were identified as non-fluorescent Pseudomonas spp.. Three bacterial isolates, $\mathrm{BS}_{-}{ }_{3}, \mathrm{BS}_{-}-_{6}$ and $\mathrm{BS}_{1}{ }_{12}$, which showed highest in vitro inhibition were selected for in vivo testing. Application of all bacterial isolates as postharvest dips, significantly reduced the anthracnose development in ripe banana. Repeated isolation confirmed the association of antagonists of C. musae only with the fruit skin of var. Seenikehel.
\end{abstract}

Key words: Antagonists, Anthracnose, Bacillus spp.,banana, Colletotrichum musae, Musa spp., Pseudomonas spp.,

\section{INTRODUCTION}

Anthracnose disease caused by Colletotrichum musae (Berk. \& Curt) von Arx. is one of the most important and widely distributed diseases of ripening and ripe banana. ${ }^{1}$ Most of the commercial banana varieties grown in Sri Lanka are susceptible to anthracnose disease. It can cause considerable postharvest losses of fruits and could therefore be considered as a great threat to the local and export market of banana.

Generally the disease is controlled by application of fungicides such as thiabendazole and benomyl at pre- and postharvest stages. However, use of fungicides for the control of banana anthracnose could lead to hazardous effects such as emergence of fungicide-resistant strains of the pathogen and oncogenic risks on the consumers. ${ }^{2,3}$ Therefore, search for alternative measures for the management of banana anthracnose is essential and biological control is a potential option.

Biological control agents could be effectively used in controlling postharvest diseases over preharvest diseases. ${ }^{2}$ Several species of bacteria, yeast and filamentous fungi have been identified as potential antagonists in controlling

Corresponding author. 
many postharvest diseases of horticultural crops. ${ }^{2-5}$ Moreover, potential antagonists of different Colletotrichum species, their modes of action and potential sources of these antagonists have been well documented. ${ }^{2,3,6}$

However, the literature available on antagonists of C. musae is limited and this study was conducted to investigate the potential antagonists of $C$. musae and to determine their ability in inhibiting C. musae.

\section{METHODS AND MATERIALS}

\section{Isolation of the pathogen}

Fruits of three different banana varieties \{i.e. Embon (AAA), Anamalu (AAA) and Kolikuttu (AAB)\}, showing typical anthracnose symptoms were used for the isolation of the pathogen. The fruits were collected from seven different agroecological regions of Sri Lanka, WL2 (Mawanella), WL3 (Gampaha), WL4 (Kalutara), WM2 (Peradeniya), WU3 (Kotmale), IL1 (Kurunegala) and IM3 (Digana). Single spore cultures were maintained on Potato Dextrose Agar (PDA) containing $125 \mathrm{ppm}$ streptomycin. Fungal colony and spore morphology were used for the identification of the pathogen. ${ }^{7}$.

\section{Confirmation of pathogenicity}

Pathogenicity of Colletotrichum musae isolates $\mathrm{I}_{1}$ and $\mathrm{I}_{2}$ were tested on the three varieties of banana, Embon, Anamalu and Kolikuttu under laboratory conditions. Mature but unripe banana fruits were inoculated by wiping the fruit skins with sterile cotton wool swabs dipped in Colletotrichum conidia suspensions having a concentration of $1 \times 10^{7}$ conidia/ml. Fruits of similar conditions but with no inoculation of $C$. musae were maintained for all three varieties as controls. Each treatment was replicated four times according to a completely randomized design. Fruits were incubated at $28^{\circ} \mathrm{C}$ for $5 \mathrm{~d}$ under high $\mathrm{RH}$ conditions. Number of lesions/fruit and rate of disease development were recorded and treatments were compared by ' $t$ ' test.

\section{Sources of antagonists}

Fruit skins of mature but unripe banana were used as the sources for antagonists. Two varieties of banana, Embon (highly susceptible to anthracnose) and Seenikehel (resistant to anthracnose) were selected for the exploration of antagonists. Fruits of variety Embon were collected from Peradeniya, Mawanella and Kandy market whereas the fruits of variety Seenikehel were collected from Peradeniya, Nugegoda and Manning market, Colombo. 


\section{Isolation of resident microflora on fruit skin}

Fruit skins were swabbed with sterile cotton wool and added into $40 \mathrm{ml}$ of sterile distilled water. Five fruits from each variety (i.e. Seenikehel and Embon) were used to obtain skin washings. The skin washings obtained from a particular variety and also belonging to the same location were pooled. Dilution series were prepared from each of the pooled mixtures and $1 \mathrm{ml}$ aliquots from the dilutions of $1 \times 10^{-5}$ were spread on Nutrient agar(NA) and Malt extract agar (MEA) containing $200 \mathrm{ppm}$ of streptomycin. NA was used to isolate bacteria and MEA with antibiotic was used for yeast and filamentous fungi. ${ }^{6}$

Isolation of resident microflora from fruit skins of the two varieties was repeated by using fruits collected from two localities in WM2 region which were different to the previous collection points of banana.

The bacterial and fungal isolates of the two varieties isolated separately were given code numbers on the following basis: BS1 = Bacterial isolates from var. Seenikehel at first isolation, FS1 = Fungal isolates from var. Seenikehel at first isolation, BE1 = Bacterial isolates from var. Embon at first isolation and FE1 = Fungal isolates from var. Embon at first isolation. Similarly, bacterial and fungal isolates from repeated isolation were denoted with " 2 ".

\section{Screening for antagonism in vitro}

Morphologically different bacterial and fungal isolates which were grown on NA and MEA from the fruit skins of banana were tested individually for their antagonism. Growth inhibition of $C$. musae by the resident fungi and bacterial isolates of banana fruit skin were tested as follows: A plug of $C$. musae $(7 \mathrm{~mm}$ diameter) obtained by a cork borer from the single spore cultures grown on MEA, was placed on the centre of a PDA plate. Either a bacterial or a fungal isolate obtained from fruit skins was inoculated on to the PDA plate having a $2.5 \mathrm{~cm}$ distance from the centre of the $C$. musae plug. Four replicates per isolate of the antagonist were tested. Both isolates of C. musae were tested separately against antagonistic effect of the different bacterial and fungal isolates. PDA plates having only a plug of $C$. musae $(7 \mathrm{~mm}$ diameter) were maintained as control treatments. Plates were incubated at $28^{\circ} \mathrm{C}$ for $5 \mathrm{~d}$ and colony diameter of C. musae was measured. 


\section{Determination of the inhibition of C. musae by antagonists in vitro}

Percentage growth inhibition of C. musae was calculated as follows:

$$
\% \text { Growth inhibition }=\frac{\mathrm{D}_{1}-\mathrm{D}_{2}}{\mathrm{D}_{1}} \times 100
$$

Where,

$\mathrm{D}_{1}=$ Diameter of $C$. musae colony in the control treatment

$\mathrm{D}_{2}=$ Diameter of $C$. musae colony subjected to antagonism

\section{Identification of the bacterial antagonists}

Identification keys described by Buchanan \& Gibbons ${ }^{8}$ were used. The tests included single colony and cell morphology, motility, Gram staining, heat test $\left(10 \mathrm{~min}\right.$ at $80^{\circ} \mathrm{C}$ ), Oxidation/fermentation test by Hugh and Leifson, presence of fluorescent pigments on King's B medium, Kovacs oxidase test and lactose fermentation test (growth on MacConkey agar).

\section{Testing for in vivo inhibition by bacterial antagonists}

Three bacterial isolates, $\mathrm{BS} 1-_{3}, \mathrm{BS} 1_{-}$and $\mathrm{BS} 1-_{12}$, (obtained from the initial isolation) which showed high antagonism in vitro were screened in vivo. Mature but unripe fruits of var. Embon were used. These fruits were taken from a home garden grower at Rambukkana (WL2), Sri Lanka, where bananas are grown more prevalently. Eight treatments were used and each treatment was replicated ten times according to a completely randomized design.

$\mathrm{T} 1$ = Banana fruits without any treatment

$\mathrm{T} 2$ = Banana fruits dipped in bacterial suspension $\mathrm{BS}_{-}-_{3}$

$\mathrm{T} 3$ = Banana fruits dipped in bacterial suspension BS1- ${ }_{6}$

$\mathrm{T} 4=$ Banana fruits dipped in bacterial suspension $\mathrm{BS}{ }_{-12}$

T5 = Banana fruits inoculated with $C$. musae only

T6 = Banana fruits inoculated with C. musae and dipped in bacterial suspension $\mathrm{BS} 1_{-}$

$\mathrm{T} 7$ = Banana fruits inoculated with $C$. musae and dipped in bacterial suspension BS1- 6

T8 = Banana fruits inoculated with $C$. musae and dipped in bacterial suspension $\mathrm{BS}_{12}$ 
Banana fruits used in all treatments except the $\mathrm{T} 1$ treatment, were surface sterilized twice using $10 \% \mathrm{NaOCl}+$ Tween 20 for $10 \mathrm{~min}$. Upon sterilization the fruits were washed 4 times using sterile distilled water. Conidial suspensions of C. musae were prepared by scraping the conidia masses developed on MEA and suspending in sterile distilled water. Preparation of bacterial suspensions was done by scraping bacterial isolates grown on NA medium and suspending in sterile distilled water.

The concentration of bacterial and $C$. musae conidial suspensions was $1 \times 10^{6}$ cells/conidia per $\mathrm{ml}$. Concentration of the bacterial suspension was determined using a calibration curve when the absorbence of the suspension was 0.1 at $620 \mathrm{~nm}^{9}$

Surface sterilized fruits were air-dried and T5, T6 and T7 fruits were inoculated with the conidia suspension of C. musae for $1 \mathrm{~min}$. Fruits of T6, T7 and T8 were air-dried upon the inoculation of $C$. musae and dipped in respective bacterial suspensions for $1 \mathrm{~min}$.

The fruits were incubated at $28^{\circ} \mathrm{C}$ for $10 \mathrm{~d}$ and the treatment effects were observed. Severity of disease development was assessed by using the following disease index: $0=$ no symptoms on the fruit, $1=1-10 \%$ symptoms/fruit, $2=11$ $20 \%$ symptoms/fruit, $3=21-35 \%$ symptoms/fruit, $4=36-50 \%$ symptoms/fruit, $5=51-65 \%$ symptoms/fruit, $6=66-80 \%$ symptoms/fruit, $7=81-100 \%$ symptoms/ fruit. Treatment effect on the symptom development was tested and compared by Kruscal-Wallis test.

Similarly, the effect of bacterial isolate BS2- ${ }_{1}$, obtained from the repeated isolation was tested for the reduction in symptom development on banana.

\section{RESULTS}

\section{Isolation of pathogen}

According to fungal colony and spore morphology, pathogen isolated from banana varieties Embon, Anamalu and Kolikuttu was identified as C. musae. ${ }^{7}$ Infected banana varieties gave two morphologically different $C$. musae isolates (i.e. $I_{1}$ - pinkish orange, sparse, flat mycelial growth and $I_{2}$ - cottony white, pluffy mycelial growth). Isolate $\mathrm{I}_{1}$ was associated with all three varieties whereas the isolate $\mathrm{I}_{2}$ could be isolated only from varieties Anamalu and Kolikuttu. 


\section{Confirmation of the pathogenicity}

Banana varieties, Embon, Anamalu and Kolikuttu, inoculated with two isolates of C. musae showed significantly high number of lesions/ fruit and rate of disease development than the controls $(P=0.05)$. Therefore the pathogenicity of both isolates of $C$. musae was confirmed.

\section{Isolation of resident microflora on fruit skin}

In the initial isolation, var. Seenikehel gave 17 different bacterial isolates and 10 fungal isolates. Variety Embon recorded 8 different bacterial isolates and 6 fungal isolates. Initial differentiation of bacteria and fungi was done according to their colony morphology.

Repeated isolation gave 3 morphologically-different bacterial isolates and 2 fungal isolates from var. Seenikehel, whereas var. Embon recorded 2 bacterial and 4 fungal isolates.

\section{Screening for antagonism in vitro}

Out of the bacterial and fungal isolates of var. Seenikehel, 9 bacterial isolates

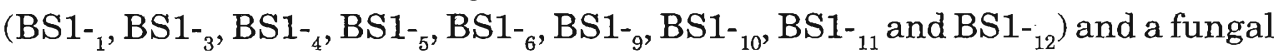
isolate showed antagonistic effect on $C$. musae in vitro. Bacterial isolates showed an average of 46 and $43 \%$ inhibition of the $C$. musae isolates $\mathrm{I}_{1}$ and $\mathrm{I}_{2}$ respectively (Figure 1). An average of $30 \%$ inhibition of the two isolates of the pathogen was given by the fungal antagonist.

Two bacterial isolates, BS2- $-_{1}$ and ${\mathrm{BS} 2-_{2}}_{2}$, obtained from var. Seenikehel by the repeated isolation showed 100 and $48 \%$ growth inhibition of $C$. musae respectively. However, in both isolations none of the bacteria or fungi of var. Embon showed any inhibition of $C$. musae.

\section{Identification of bacterial antagonists}

Six bacterial isolates out of the 9 isolated firstly from var. Seenikehel (BS1-

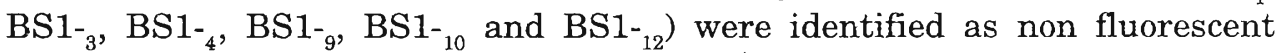
Pseudomonas species. Other antagonistic bacteria ( $\mathrm{BS}_{-}-_{5}, \mathrm{BS} 1_{-6}$, and $\mathrm{BS} 1-_{11}$ ) remained unidentified as they showed contrasting characteristics [i.e. BS1- ${ }_{5}=$

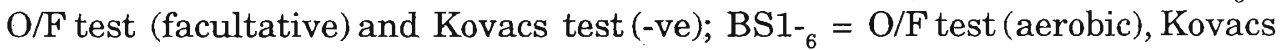
test (-ve) and $\mathrm{BS}_{-11}=\mathrm{O} / \mathrm{F}$ test (facultative), Kovacs test (+ve)] to a non fluorescent Pseudomonas spp. Fungal isolate was identified as a member of the Deuteromycotina group.

Only the highly antagonistic bacterium obtained from the repeated isolation

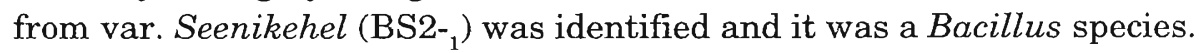




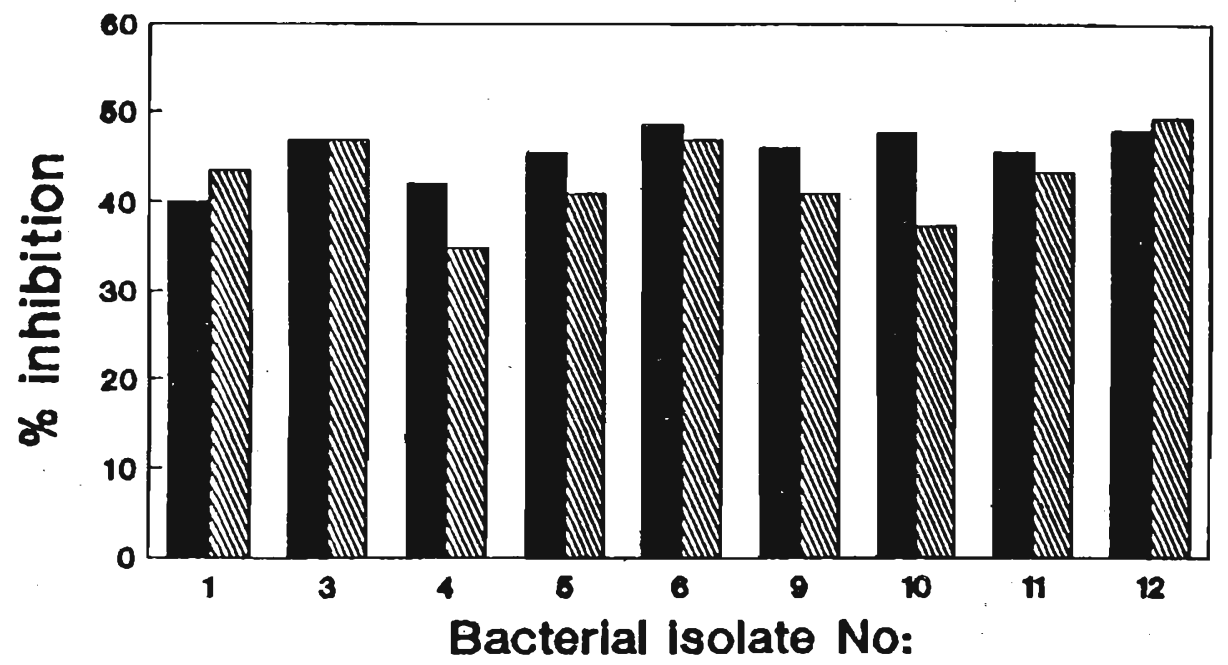

W loolate 1 AIIIII / solato 2

Figure 1: \% inhibition of Colletotrichum musae isolates $\left(I_{1}\right.$ and $\left.I_{2}\right)$ by the nine different isolates of antagonistic bacteria.

\section{In vivo screening of bacterial antagonists}

Ability of inhibiting $C$. musae by the selected three bacterial isolates as a postharvest dip is given in the Figure 2.

Application of bacterial suspensions, $\mathrm{BS} 1-_{3}, \mathrm{BS} 1-_{6}$ and $\mathrm{BS} 1-_{12}$ showed a significant reduction in disease development on ripe banana $(P=0.05)$. Postharvest dips of above three bacterial isolates reduced the anthracnose development in both field infested (T2, T3 \& T4) and artificially inoculated fruits (T6, T7 \& T8) significantly ( $\mathrm{P}=0.05)$. Among the bacterial isolates $\mathrm{BS} 1-_{12}$ gave the highest reduction of disease development. However, the capacity of reducing the disease development showed no significant difference among the three bacterial isolates (i.e. $\mathrm{BS}_{-}{ }_{3},{\mathrm{BS} 1-_{6}}$ and $\mathrm{BS} 1-_{12}$ ).

Fruits which were not treated with bacterial isolates produced salmon-pink colour conidia masses on the lesions ten days after incubation. In contrast, the fruits treated with bacterial suspensions did not show any sign of conidia on lesions after ten days of incubation. However, postharvest dips of Bacillus spp. $\left(\mathrm{BS}_{2}{ }_{1}\right)$ did not show a reduction of disease development on fruits. 


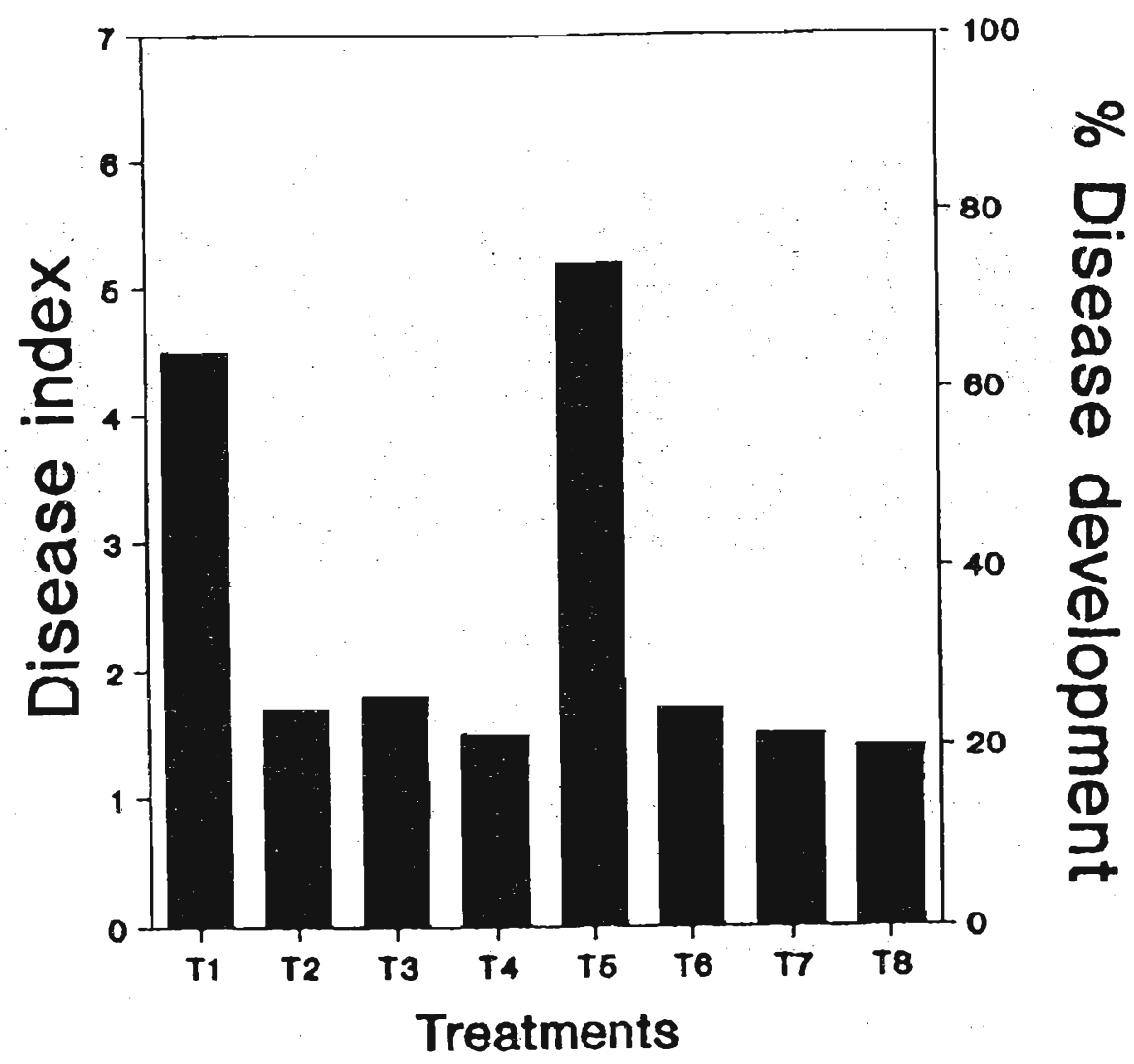

Figure 2: \% disease development and the disease indices of banana fruits treated with three high performing bacterial isolates as postharvest dips.

\section{DISCUSSION}

All the tested fruits of variety Seenikehel did not show any symptom of anthracnose development until two weeks from the onset of ripening. Therefore, var. Seenikehel was selected as a potential source of antagonists of $C$. musae as it could be considered as a potential niche for the exploration of antagonists. ${ }^{10}$

Many bacteria and fungi associated with the fruit skin of var. Seenikehel showed promising antagonistic potential against $C$. musae in vitro. However, due to practical limitations involved with fungi in the development as biocontrol agents of postharvest diseases of fruits, ${ }^{6}$ only the bacterial antagonists were considered for detailed studies. Physical problems expected in establishing fungi and disease development on fruits by fungi could be considered as the practical limitations of fungal antagonists. 
Among the antagonists associated with var. Seenikehel, there were nonfluorescent Pseudomonas and Bacillus spp.. Fluorescent and non fluorescent type Pseudomonas spp. and Bacillus spp. associated on phyllosphere have been reported as antagonists of several Colletotrichum spp. ${ }^{2,6,11}$ Pseudomonas fluoresens, a fluorescent producer has been reported as an antagonist of $C$. gloeosporioides of mango and $P$. cepacia, a non fluorescent type as an antagonist of Colletotrichum lagenarium. ${ }^{2}$ Bacillus subtilis has been reported as a potential antagonist of $C$. gloeosporioides in mango and $C$. lindemuthianum ${ }^{4}$ in bean. Additionally, Pseudomonas spp. and Bacillus spp. have shown antagonistic effect on a broad spectrum of postharvest pathogens. ${ }^{2}$ Presence of antagonistic microflora on the fruit skin could have an effect on the resistance to anthracnose in var. Seenikehel. This effect was more evident due to the absence of antagonists on var. Embon which are highly susceptible to anthracnose. Since repeated isolations of var. Seenikehel from different locations confirmed antagonism against $C$. musae, it could be a characteristic feature of var. Seenikehel in contrast to the anthracnose susceptible variety of banana. However, more investigations are needed for a conclusive statement and the antagonists associated with var. Seenikehel have to be tested for their in vivo efficiency prior to its development as potential biocontrol agents.

Application of bacterial isolates $\mathrm{BS} 1-_{3},{\mathrm{BS} 1-{ }_{6}}$ and $\mathrm{BS} 1-_{12}$ having concentrations of $1 \times 10^{6} \mathrm{cell} / \mathrm{ml}$ as postharvest dips reduced the anthracnose development in var. Embon. Reduction of disease development could be due to the inhibition of $C$. musae by the antagonists associated with var. Seenikehel. Similar observations have been found with several Colletotrichum species due to the effect of antagonistic microflora associated with fruit surfaces and phyllosphere of different fruits. ${ }^{6,11,12}$ However, the inhibition of $C$. musae due to antagonistic microflora of the fruit skin of var. Seenikehel needs more research evidence for its confirmation as the sole factor responsible for the antagonism.

In vivo efficiency of Bacillus spp. was not successful despite its high performance in vitro. Similar observations have been recorded on the in vivo antagonistic ability of Bacillus subtilis against $C$. gloeosporioides as a microorganism associated with the fruit peel of mangoes. ${ }^{6}$ However, the potential use of Bacillus spp. in vivo needs to be tested using different application methods.

Further identification of the antagonists upto their species level is needed. Investigations on storage life, suitable application methods, effects on other postharvest pathogens, toxicology, mode of action and cultural practises favourable for the establishment of the antagonists at preharvest conditions are some of the studies that could be done for the development of the above antagonists as biocontrol agents of $C$. musae. 


\section{References}

1. Sutton B.C. \& Waterston J.M. (1970). CMI Descriptions of pathogenic fungi and bacteria (No. 222).

2. Jeffries P. \& Koomen I. (1992). Strategies and prospects for biological control of diseases caused by Colletotrichum. In Colletotrichum: biology, pathology and control (Ed. J.A. Bailey \& M.J. Jeger) pp 337-357. CAB International, Wallingford.

3. Wilson C.L. \& Wisniewski M.E. (1989). Biological control of postharvest diseases of fruits and vegetables: an emerging technology. Ann. Rev. Phytopathology 27: 425-41.

4. Melgarejo P., Carrillo R. \& Sagasta E.M. (1986). Potential for biological control of Monilinia laxa. Crop Protection 5: 422-426.

5. Roberts R.G.(1990). Postharvest biological control of grey mold of apple by Cryptococcus laurentii. Phytopathology. 80: 526-530.

6. Koomen I. \& Jeffries P. (1993). Effects of antagonistic microorganisms on the postharvest development of Colletotrichum gloeosporioides on mango. Plant Pathology 42(2): 230-237.

7. Sutton B.C.(1992). The genus of Glomerella and its anamorph Colletotrichum. In Colletotrichum: biology, pathology and control (Ed. J.A. Bailey \& M.J. Jeger) pp. 1-26. CAB International, Wallingford.

8. Buchanan R.E. \& Gibbons N.E. (1975). Bergey's manual of determinative bacteriology. 8th edition. 1268 pp. Williams and Wilkins. Baltimore.

9. Kiraly Z., Klement Z., Solymosy F. \& Voros J. (1974). Methods in plant pathology. pp 161-164. Elsevier Scientific Publishing Company. Amsterdam.

10. Cook R.J. \& Barker K.F. (1983). The nature and practice of biological control of plant pathogens. 539 pp. American Phytopathology Society, St. Paul.

11. Korsten L., De Villiers E.E:, Wehner F.C. \& Kotze J.M. (1993). A Review of biological control of postharvest diseases of tropical fruits. In: Postharvest handling of tropical fruits (Ed. B.R. Champ, E. Highley \& G.I. Johnson) pp. 172-185. (ACIAR Proceedings No. 50.) Australia.

12. Farungsan N., Farungsan U.\& Sangchote S. (1993). Preliminary investigations of microorganisms antagonistic to Colletotrichum gloeosporioides obtained from Rambutan. In: Postharvest handling of tropical fruits (Ed. B.R.Champ, E. Highley \& G.I.Johnson) pp. 375-377. (ACIAR Proceedings No. 50.) Australia. 